\title{
Research on the Stage of Regional Low-Carbon Economy Development, Influencing Factors and Policy Effects-Evidence from Jiangxi Province
}

\author{
Siqi Yang ${ }^{1, * * *}$, Shiyi Jiang ${ }^{2, *}$, Zhiying Zhang ${ }^{3}$ \\ ${ }^{1}$ Jiangxi University of Finance and Economics, School of Economics, 330013 Nanchang, China \\ ${ }^{2}$ Jiangxi University of Finance and Economics, International School, 330013 Nanchang, China \\ ${ }^{3}$ Jiangxi University of Finance and Economics, School of Accountancy, 330013 Nanchang, China
}

\begin{abstract}
This paper considers the pilot policy of low carbon cities as a "natural experiment". Firstly, the EKC curve is plotted using panel data of Jiangxi Province and eight prefectural-level cities in the province from 2010 to 2018, and it is judged that Jiangxi Province's economy is still in the rising part of the left side of the curve, and economic development is still occurring at the cost of carbon emission growth. Secondly, fixed-effects model was used to investigate the factors that influence $\mathrm{CO}_{2}$ emissions, and it was discovered that industrial structure and the intensity of environmental management had an impact on carbon emissions. Thirdly, the Difference-in-Differences model is applied to evaluate the effect of low carbon city pilot policies, and it is discovered that the policies have a positive effect on energy conservation and emissions reduction. Finally, based upon the empirical results, suggestions for the future development of a low-carbon economy in Jiangxi Province are made in three areas: low-carbon production, environmental governance and supervision, and policy radiation.
\end{abstract}

\section{Introduction}

Jiangxi Province, as an important development and environmental protection area in China, is dealing with the dual pressures of economic development and environmental protection in its growth. In the early days, Jiangxi Province's growth policy followed the old road of development before governance, neglecting the establishment of a low-carbon economy. In 2010, the National Development and Reform Commission issued the Announcement on the Piloting of Low-Carbon Provinces and Low-Carbon Cities and launched three batches of low-carbon pilot cities one after another. The construction of low-carbon cities shows a progressive development path from pilot to gradual proliferation [1]. Based on this, it is particularly important to further deepen the research on the development of low-carbon economy and the effect of low-carbon policy implementation in Jiangxi Province.

\section{An Empirical Study on the Environmental Kuznets Curve}

\subsection{Indicator selection and model construction}

In this paper, $\mathrm{CO}_{2}$ emissions in Jiangxi Province is chosen as an indicator of the degree of environmental impact and use GDP per capita in Jiangxi Province as an explanatory variable. The general form of the environmental Kuznets curve is constructed

$$
C O_{2}=\beta_{0}+\beta_{1} G D P P+\beta_{2}(G D P P)^{2}
$$

Where GDPP is Jiangxi Province's GDP per capita, $\mathrm{CO} 2$ is Jiangxi Province's $\mathrm{CO}_{2}$ emission, with its formula being primarily expressed by the product of Jiangxi Province's major energy consumption and its carbon emission factor:

$$
\mathrm{CO}_{2}=\sum E_{i} * N V C_{i} * C E F_{i} * C O F_{i}
$$

where $i$ represents an energy type, $\mathrm{E}$ represents the consumption of the ith energy source, $N C V$ is the average net calorific value of the ith energy source provided in the annex of the China Energy Statistics Yearbook, $C E F$ $(\mathrm{kg} / \mathrm{TJ})$ is the carbon emission parameter of the ith energy source provided by IPCC (2013), and CFO is the carbon oxidation factor of the ith energy source.

\subsection{Modeling Results}

Based on the statistical data of GDP per capita and $\mathrm{CO}_{2}$ emissions in Jiangxi Province from 2010 to 2018, with GDP per capita and its square as the independent variable and $\mathrm{CO}_{2}$ emissions in Jiangxi Province taking the natural logarithm as the dependent variable, the regression results of the environmental Kuznets curve model for $\mathrm{CO}_{2}$ in Jiangxi Province were obtained using stata 15 as follows.

*Corresponding author: siqiyang0809@163.com 
Table1. Fitted Coefficients of $\mathrm{CO}_{2}$ EKC Curves in Jiangxi Province

\begin{tabular}{ccccc}
\hline Explained Variables $\mathrm{CO}_{2}$ & Coefficient & Std.Error & t-Statistic & Prob. \\
\hline$\beta_{1}$ & 5155.808 & 671.0224 & 7.68 & 0.000 \\
$\beta_{2}$ & -0.048557 & 0.0127745 & -3.8 & 0.003 \\
$\beta_{0}$ & 52470000 & 7666477 & 6.84 & 0.000 \\
\hline
\end{tabular}

The shape of the curve between $\mathrm{CO}_{2}$ emissions and GDP per capita in Jiangxi Province from 2010 to 2018 resembles an "inverted U-shaped" relationship. It is demonstrated that there is a natural Kuznets curve relationship for carbon emissions in Jiangxi Province. Since the inflection point of Jiangxi's per capita GDP needs to reach RMB 53,090.265 per capita, Jiangxi Province is still in the left half of the curve, and is in a continuing upward trend, which has not yet reached the turning point. It indicates that the curve of the relationship between average $\mathrm{CO}_{2}$ emissions and per capita GDP in Jiangxi Province has not yet entered the late industrialization development stage of the environmental Kuznets curve.

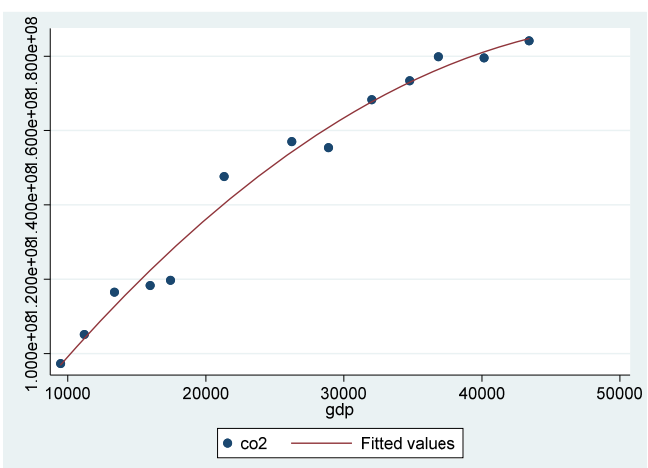

Figure 1. Fitted EKC Curve of $\mathrm{CO} 2$ in Jiangxi Province

\section{Fixed effects model of the factors influencing $\mathrm{CO}_{2}$ emissions}

\subsection{Model Building}

Considering the province's growth features, this paper uses the share of secondary industry and the intensity of environmental management as the key explanatory indicators to investigate the influencing variables of $\mathrm{CO}_{2}$ emissions in Jiangxi Province. The share of secondary industry represents a region's level of industrial growth. In general, the higher the share of industry, the more serious the carbon emission. Green production, on the other hand, may be able to replace the original energyintensive businesses, lowering carbon emissions. Furthermore, the region's level of environmental governance intensity can represent the province's determination and ability to establish a low-carbon economy, which has an impact on $\mathrm{CO}_{2}$ emissions. This paper included the number of year-end resident population, gross regional product, total energy consumption, R\&D investment in science and technology, the number of governance facilities, and foreign direct investment as control variables in addition to the main explanatory variables. The initial econometric model was constructed as follows:

$$
C O_{2 i t}=\alpha_{0}+\alpha_{1} I S_{i t}+\alpha_{2} G I_{i t}+\alpha_{3} X_{i t}+\varepsilon_{i t}
$$

where $\mathrm{CO}_{2}$ is the $\mathrm{CO}_{2}$ emissions of each municipality, IS is the share of secondary industry, $G I$ is the intensity of environmental management, $X$ is the relevant control variable, and $\varepsilon$ is the random disturbance term of the model. The detailed variables are described as follows:

Table2. Variables

\begin{tabular}{|c|c|c|c|c|}
\hline Type & Symbol & Variable Name & Representative Indicators & $\begin{array}{l}\text { Symbol } \\
\text { prediction }\end{array}$ \\
\hline Explained Variables & $\mathrm{CO}_{2}$ & $\begin{array}{ll}\text { Carbon } & \text { Dioxide } \\
\text { Emissions } & \end{array}$ & Total Carbon Dioxide Emissions & \multirow{8}{*}{$+(-)$} \\
\hline \multirow[b]{2}{*}{$\begin{array}{l}\text { Explanatory } \\
\text { Variables }\end{array}$} & IS & Industrial Structure & Share of secondary industry in GDP & \\
\hline & GI & $\begin{array}{l}\text { Environmental } \\
\text { Management Intensity }\end{array}$ & $\begin{array}{l}\text { Number of exhaust gas treatment } \\
\text { equipment }\end{array}$ & \\
\hline \multirow{5}{*}{ Control Variables } & GDP & Economic Scale & Regional Gross National Product & \\
\hline & POP & Population Size & Regional Resident population & \\
\hline & ES & Energy Consumption & Total Energy Consumption & \\
\hline & TEC & Technology Level & by Public Expenditure & \\
\hline & FIP & $\begin{array}{l}\text { Foreign } \\
\text { Level }\end{array}$ & $\begin{array}{l}\text { Amount of Foreign Investment Directly } \\
\text { Utilized }\end{array}$ & \\
\hline
\end{tabular}

This research examines panel data of eight prefectural-

\subsection{Data sources}

level cities in Jiangxi Province from 2010 to 2018. The consumption of various types of energy is based on the 
Jiangxi Province Statistical Yearbook (2010-2018); indicators such as energy emission coefficients are based on the China Energy Statistical Yearbook and IPCC (2013); and the number of year-end resident population is based on the China Energy Statistical Yearbook and IPCC (2013), the number of year-end resident population, gross regional product, share of secondary industry structure, investment in science and technology $R \& D$, number of governance facilities, and the amount of foreign direct investment in each city are obtained from the CENSUS City Statistical Yearbook (2010-2018).

\subsection{Empirical results}

Based on the panel data of eight cities in Jiangxi Province, the empirical analysis of Model 1 and Model 2 was conducted using stata. The original hypothesis that there is no systematic difference between random effects and fixed effects should be rejected based on the results of the Hausman test, implying that the fixed effects model is more effective. Therefore, in this paper, a fixed-effects model with panel data is applied to estimate the influencing factors of $\mathrm{CO}_{2}$ in Jiangxi Province, and the final results are as following:

Table3. Table of fixed effects model coefficients

\begin{tabular}{cccc}
\hline $\begin{array}{c}\text { Explanatory } \\
\text { Variables }\end{array}$ & Coefficient & $\mathrm{z}$ value & Prob. \\
\hline IS & -0.1556229 & -3.81 & 0.000 \\
GP2 & -0.0016909 & 4.30 & 0.000 \\
GDP & $-3.48 \mathrm{e}-7$ & 6.20 & 0.000 \\
POP & $4.30 \mathrm{e}-7$ & -7.97 & 0.000 \\
ES & 0.00492373 & -4.54 & 0.000 \\
TEC & $5.66 \mathrm{e}-6$ & 0.8 & 0.424 \\
FIP & $-2.96 \mathrm{e}-0.6$ & -0.28 & 0.779 \\
cons & 11.19594 & 7.81 & 0.000 \\
\hline
\end{tabular}

In terms of explanatory variables, the coefficient of the industrial structure variable is negative and significant at the $1 \%$ confidence level, indicating that the introduction of industry in Jiangxi Province is primarily green production enterprises, and the former industrial enterprises have been replaced by related low-pollution firms, low-carbon production has become the trend in secondary industry. The environmental management variable's coefficient is likewise negative and significant at the $1 \%$ confidence level, indicating that the establishment of environmental management and exhaust gas treatment facilities in Jiangxi Province reduces carbon emissions significantly.

From the control variables, GDP, population size and total energy consumption also have a significant effect on $\mathrm{CO}_{2}$ emissions. Among them, the level of economic development has a suppressive effect on the level of carbon dioxide emissions in the region, and economic growth can bring a positive effect on the full development of a low-carbon economy. The rise in the number of residents will result in an increase in carbon emissions from living and production, making it more difficult for Jiangxi Province to establish a low-carbon economy. Carbon emissions will rise as overall energy consumption rises, indicating that Jiangxi Province continues to rely on high-carbon-emitting fossil fuels as its main source of energy.

\section{Difference-in-differences model}

\subsection{Model Setting}

The purpose of this paper is to assess the impact of low carbon city pilot policy on $\mathrm{CO}_{2}$ emissions in Jiangxi Province. Because the first batch of low carbon pilot policy is mainly at the provincial level and only one city level in Nanchang City, and the third batch of low carbon pilot policy was implemented in 2017 with a time lag, the policy effect may not yet appear. Therefore, the second batch of low-carbon cities in 2012, Jingdezhen and Ganzhou, are employed as an experimental group. By comparing the $\mathrm{CO}_{2}$ emissions of the experimental group (pilot areas) with those of the control group (non-pilot areas) before and after the low carbon pilot policy, and excluding factors that do not change over time and are not observable, the effect of the low carbon pilot policy on carbon emissions is reasonably assessed. The econometric model is established as follows:

$$
\begin{aligned}
\mathrm{CO}_{2}= & \beta_{0}+\beta_{1} \text { treat }+\beta_{2} \text { year }+\beta_{3} \text { year } * \text { treat } \\
& +\sum \rho \text { Control }+\lambda_{t}+\sigma_{c}+\varepsilon
\end{aligned}
$$

Within the model, $\mathrm{CO}_{2}$ is the $\mathrm{CO}_{2}$ emission of the city in year $t$. Treat is the pilot city dummy variable, if the city is a pilot city, it is "1", and vice versa, it is "0". year is the policy time dummy variable, after 2012, it is "1", and vice versa, it is " 0 "; The coefficient of year $\times$ treat is the cross product of treat and year, and its coefficient $\beta 3$ is the policy effect that is the most concerned in this paper; Control is a series of control variables; $\lambda \mathrm{t}, \sigma \mathrm{c}$ are the fixed effects of time and city fixed effects; $\varepsilon$ denotes the random disturbance term [2].

\subsection{Empirical Analysis}

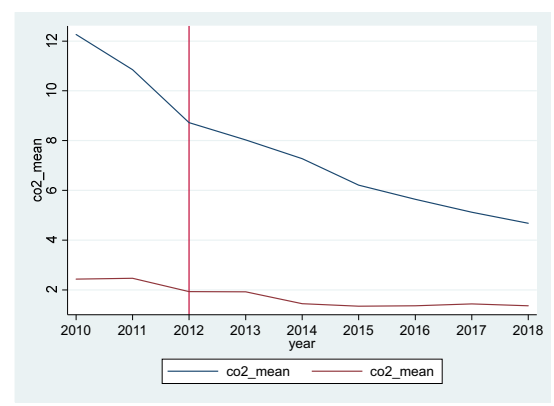

Figure 2. Parallel Trend Chart

The Difference-in-Differences parallel trend graph shown above demonstrates the year on the horizontal axis and the average value of $\mathrm{CO}_{2}$ emissions on the vertical axis. Using the second batch of low-carbon pilots issued in 2012 as a dividing line, the pilot regions are generally greater than the non-pilot regions with time change in the non-pilot period (2010-2012), but they roughly show parallel patterns. And the pattern of change is consistent: during the pilot period (2013-2016), $\mathrm{CO}_{2}$ emissions in lowcarbon pilot areas fell rapidly. As a result, the parallel 
trend of Difference-in-Differences hypothesis is correct. The following are the results of the Difference-inDifference model:

Table4. Difference-in-Differences Results

\begin{tabular}{cccc}
\hline Variables & Coefficient & z value & Prob. \\
\hline year $\times$ treat & -4.586 & -2.02 & 0.049 \\
GI & -0.011 & -2.54 & 0.014 \\
GDP & $-2.86 \mathrm{e}-7$ & 0.49 & 0.629 \\
POP & $2.85 \mathrm{e}-5$ & 0.80 & 0.425 \\
ES & -0.1544 & -2.08 & 0.043 \\
TEC & $-7.68 \mathrm{e}-0.6$ & -0.21 & 0.835 \\
FIP & $-4.84 \mathrm{e}-5$ & -0.77 & 0.447 \\
\hline
\end{tabular}

The regression results of the double difference model with the inclusion of time and city fixed effects show that the coefficient of year $\times$ treat is negative and significant at the $5 \%$ level, which indicates that the low-carbon city pilot policy has an energy-saving and emission-reducing effect on $\mathrm{CO}_{2}$ emissions in Jiangxi Province. The environmental governance has a substantial impact on emission reduction outcomes as well. The more intense environmental governance is, the more obvious the effect of emission reduction policies becomes.

\section{Research conclusions and policy recommendations}

\subsection{Research conclusion}

Based on the environmental Kuznets curve theory, this paper first verifies the relationship between economic development and carbon emissions in Jiangxi Province, concluding that carbon emissions and economic development in Jiangxi Province are essentially in line with the "inverted U-shaped" relationship of first growth and then reduction. The calculation of the inflection point shows that Jiangxi's GDP per capita needs to reach 53,090.265 RMB when $\mathrm{CO}_{2}$ emissions are decreasing. Jiangxi Province is still in the left half of the curve, continuing its upward trend, and has not yet reached the turning point.

Then, the fixed-effects model is used to investigate the major elements that influence each city's $\mathrm{CO}_{2}$ emissions. The coefficient of industrial structure variable is negative, indicating that the introduction of industry in Jiangxi province is now primarily green production enterprises, with former industrial enterprises being replaced by relevant low-pollution enterprises, and low-carbon secondary industry production has become a trend. At the same time, the environmental governance variable's coefficient is negative, reflecting the fact that the results of the current environmental management in Jiangxi Province are beginning to show results .

Finally, the empirical evidence shows that the coefficient of year $\times$ treat is negative and significant at the $5 \%$ level, indicating that the low carbon city pilot policy can significantly reduce $\mathrm{CO}_{2}$ emissions in Jiangxi Province, using a Difference-in-Differences model with the inclusion of time and city fixed effects for regression.

\subsection{Policy Recommendations for Low Carbon Economic Development in Jiangxi Province}

(1) It is advisable to optimize the industrial structure, realize the transition from high-polluting to low-carbon green production, and promote clean manufacturing [3]. At present, the environment-friendly industries in the Jiangxi Province region of China are in the development stage. It is necessary to improve environmental supervision and regulation to provide impetus for the development of environment-friendly industries.

(2) Strengthening the intensity of environmental governance and regulation to reduce carbon emissions. On the one hand, accelerate the construction of carbon emission governance facilities to promote the sustainable development capacity of Jiangxi Province [4]. On the other hand, in order to encourage the sound growth of a low-carbon economy, tighten legislation linked to sustainable development and raise the intensity of law enforcement.

(3) Low-carbon pilot cities, as an important regional economic development policy, have a higher positive influence on energy saving and emission reduction in Jiangxi Province. To support the transformation and upgrading of Jiangxi Province's total low-carbon economy, it is vital to fully utilize the radiation impact of the pilot cities.

\section{Acknowledgement}

*Siqi Yang and Shiyi Jiang contributed equally to this work.

\section{References}

1. Development path of Chinese low-carbon cities based on index evaluation[J] . Xiu Yang,Xue-Chun Wang,Ze-Yu Zhou. Advances in Climate Change Research . 2018

2. What drives the carbon emission in the Chinese cities?-A case of pilot low carbon city of Beijing $[\mathrm{J}]$. Liyin Shen,Ya Wu,Yingli Lou,Deheng Zeng,Chenyang Shuai,Xiangnan Song. Journal of Cleaner Production . 2018

3. Multiple Environmental Policies and Pollution Haven Hypothesis:Evidence from China's Polluting Industries. Dan,et al. Journal of Cleaner Production . 2017

4. Can a carbon emission trading scheme generate the Porter effect? Evidence from pilot areas in China[J] . Feng Dong,Yuanju Dai,Shengnan Zhang,Xiaoyun Zhang,Ruyin Long. Science of the Total Environment . 2019 